\title{
Predominant Climate Exposure Strains - Thermal Degradation Testing Compared to Historical and Future Climate Scenarios
}

\author{
Petra Rüther, Klodian Gradeci and Malin Sletnes \\ SINTEF Community. Department for architecture, building materials and constructions, \\ Høgskoleringen 7A, 7461 Trondheim, Norway, petra.ruther@sintef.no
}

\begin{abstract}
The service life of a building or structure is often presumed to be 60 years. Products usedin the building envelope are often covered by a facade material on the exterior side. Hence, the failure of these products is not easily observable, and the repair or replacement is normally not technically nor economically feasible. Thus, these products are expected to endure the entire estimated lifetime of the building. Service life prediction of these products is based on accelerated ageing tests, whose aim is to measure future possibilities of materials' durability under their expected service life. Preliminary calculations of acceleration factors are discussed and related to historical and future climate scenarios for a dataset from Calgary, Canada. The changes in temperature threshold values for this dataset is significant. Relating the measured values to a duration of a typical accelerated durability test indicates that the test duration is sufficient for a service life of 102 years according to historical climate, but only 52 years taking into account an assumed climate change.
\end{abstract}

Keywords: Durability Testing, Accelerated Ageing, Future Climate Scenarios, Exterior Applications.

\section{Introduction}

The service life of buildings and building products is presumed to be 60 years. Wall membrane and roofing products, including adhesive products, are widely used in modern building assemblies and the service life of these products that play an important role in ensuring the air and rain tightness of the buildings has to reach 60 years. Furthermore, the inspection of these products, that are often hidden from visual inspection by cladding material mounted on the outermost layer of a building, is difficult.

Wall membrane and roofing products are usually subjected to an accelerated ageing procedure (see Table 1), depending on the use of the product in question. The test standards are designed with regards to the product in question and the prevailing climate condition in the use area of the product.

The ageing procedures are often, but not always a combination of what is believed to be a realistic climatic condition: elevated temperatures, (UV) radiation, water spray, freeze-thaw cycles, to mention the most common ones. Studies on material degradation usually involve a very detailed study of the degradation mechanism. The common ground for building products is usually their application area and not the type of material. Hence, test procedures should preferably account for the climatic strains, and attempt to reproduce the climatic conditions in service (Riahinezhad et al., 2019) as correctly as possible.

While many test procedures are cycling several climatic agents, e.g. solar radiation and humidity, or humidity and elevated temperatures, this study will discuss implications for the testing in elevated temperatures, and discuss whether the effects of climate change, hence increased temperatures, need to be taken into account when designing accelerated ageing procedures. 


\section{Brief Review of Accelerated Weathering Methods}

In order to be able to link the weather conditions to accelerated ageing methods, the temperatures are compared to the elevated temperatures of some European and international test standards for products used on the exterior of wall and roof assemblies.

Table 1. Summary of the most relevant ageing procedures for building envelope materials.

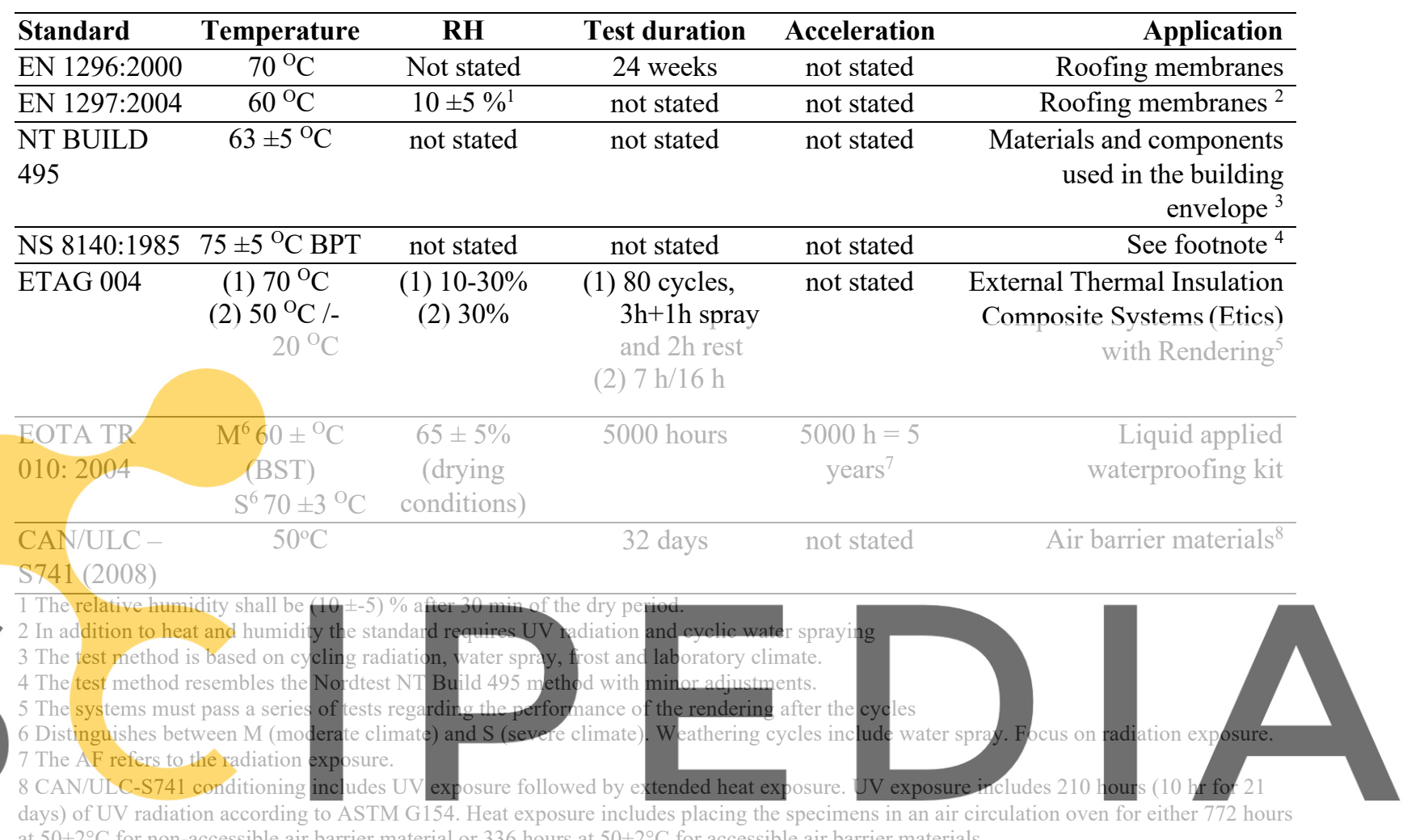

at $50 \pm 2^{\circ} \mathrm{C}$ for non-accessible air barrier material or 336 hours at $50 \pm 2^{\circ} \mathrm{C}$ for accessible air barrier materials.

Register for free at https//www.scipedia.com to download the version without the watermark

The above summary shows that most products for exterior applications in the building

envelope are tested under elevated temperatures between $50^{\circ} \mathrm{C}$ and $70^{\circ} \mathrm{C}$ for between 32 days and 24 weeks. The acceleration factors stated are usually connected to the radiation exposure and not the thermal degradation.

\section{Historical and Future Temperature Values}

The selected location is Calgary, Canada. Two sets of climate data generated in Gaur et.al.

(2019) that include the following:

- 15 historical climate data set, and

- 15 climate data set for a climate change scenario in which the global climate temperature change is forecast to be $3.5^{\circ} \mathrm{C}$.

The reader is referred to Gaur et al. (2019) for more in-depth understanding of the methodology used, while a short description follows. A merged observational climate timeseries (1986-2016) for the city of Calgary was prepared from the hourly observations (surface global horizontal irradiance, total cloud cover, rainfall, relative humidity, air temperature, station pressure, $10 \mathrm{~m}$ wind-speed and wind-direction), and daily observations of the snowdepth from the collection of all of the Environment and Climate Change Canada (ECCC) climate gauging stations located within the domains of Calgary and containing more than one year of data between the time-period: 1986-2016. The database of climatic projections from 
CanRCM4 LE, Global Climate Model (GCM), was used to extract climatic projections for Calgary spanning the historical and future time-periods. In total, 15 members of the hourly CanESM2 LE projections covering the historical and the future time-periods were extracted for the grids covering the Calgary for the generation of 15 historical and 15 projected time-series of the climate variables.

Data was analysed to find the time periods where temperatures lie above a distinct temperature threshold. Temperature steps of $10^{\circ} \mathrm{C}$ between a range of $-45^{\circ} \mathrm{C}$ and $+45^{\circ} \mathrm{C}$. Results are presented below for historical data and for the chosen climate scenario, together with averages, standard deviations and differences.

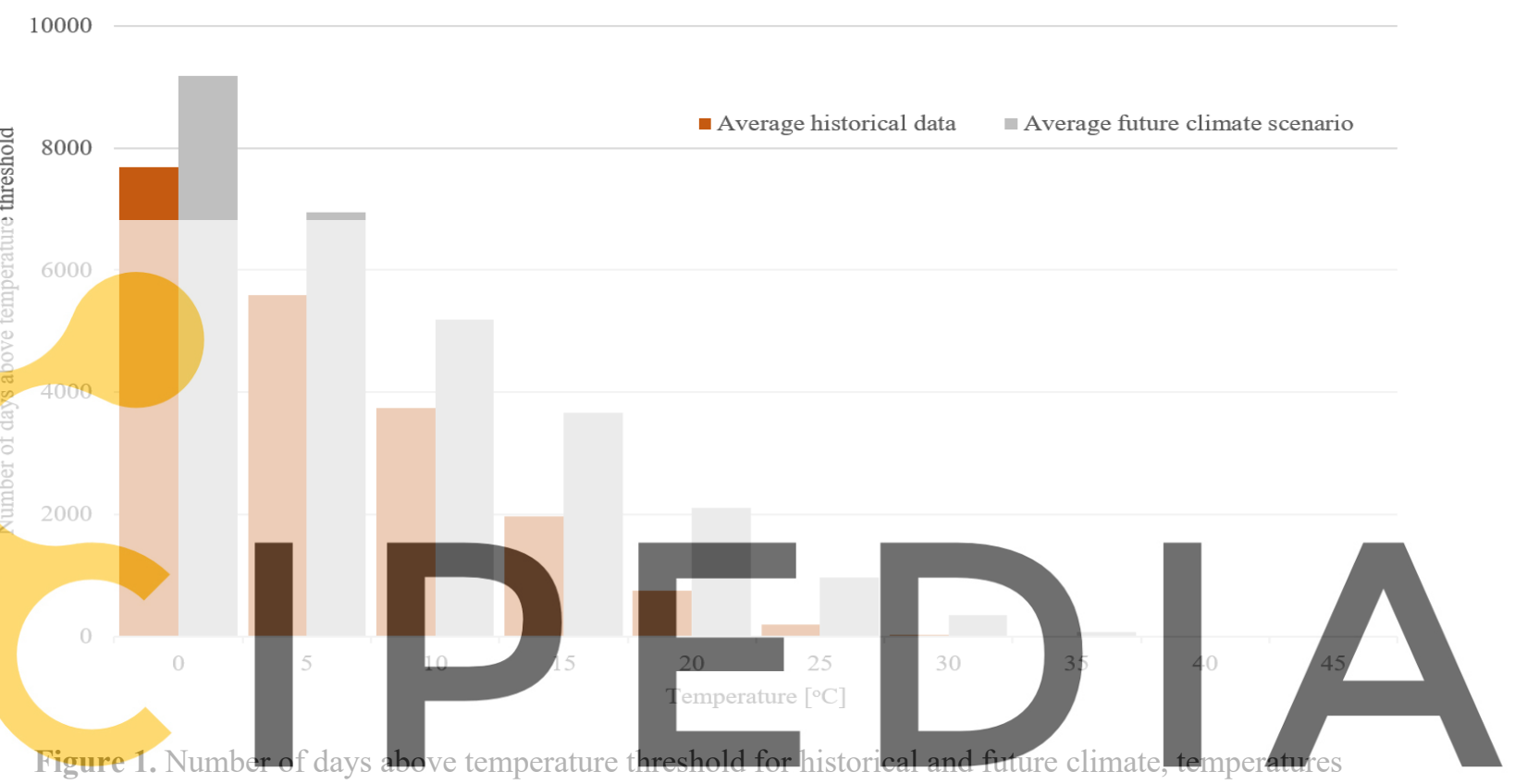
above $0^{\circ} \mathrm{C}$.

Register for free at https//www.scipedia.com to download the version without the watermark verage temperatures towards higher temperature levels. The number of days where the temperature exceeds $0^{\circ} \mathrm{C}$ increases for example by 1490 in the course of a 30-year period, or by an average of 50 days per year. For elevated temperatures the relative increase in days above the threshold value is significant: The accumulated period where the average temperature exceeds $30^{\circ} \mathrm{C}$ increased 3.52 times from 30 days to 352 days in a 30 -year period. Correspondingly, the amount of time accumulated at lower temperatures decrease

\section{Investigation of Acceleration Factors}

In order to ensure that building materials exposed to outdoor conditions have the quality to endure the desired service life, accelerated laboratory testing is conducted. A brief review of some common test methods is presented in Table 1 . The tests commonly include amongst others solar radiation and elevated temperatures between $50^{\circ} \mathrm{C}$ and $70^{\circ} \mathrm{C}$, for some test methods the temperatures are cycled and/or alternated with water spray.

The service life of buildings and building parts that are not to be replaced is often set to between 50 and 60 years (Byggforsk, 2017), for materials and components in the building envelope that are accessible for replacement between 25 and 30 years.

Hence, the durability test should aim for testing a service life of 25-30 years or 50-60 years, respectively. The common dilemma with durability testing is to keep the test duration as short 
as possible, i.e. to accelerate the test as much as possible, without generating degradation effects caused by elevated temperatures not present in a real application.

The following sections explore and discuss acceleration factors along with respective test durations for thermal degradation processes based on the above presented historical and future climate scenarios.

\subsection{Methodology}

Polymeric materials used in building materials are subject to degradation mainly caused by photoirradiation and thermal degradation. The dependence of the rate of thermal degradation on the temperature can be described by the Arrhenius law:

$$
\boldsymbol{k}=\boldsymbol{A} \cdot \boldsymbol{e}^{\left(\frac{\left(E_{a}\right.}{R \cdot T}\right)}
$$

where $\mathrm{A}$ is a pre-exponential factor, $\mathrm{E}_{\mathrm{a}}[\mathrm{J} /(\mathrm{mol} \mathrm{K})]$ is the activation energy, $\mathrm{R}=8.314 \mathrm{~J} / \mathrm{mol}$ is the gas constant, and $\mathrm{T}[\mathrm{K}]$ is the temperature. A temperature acceleration factor $\mathrm{AF}_{\text {temp }}$ may then be calculated as the ratio between the reaction rate in the accelerated weathering test $\mathrm{k}_{1}$ and the natural outdoor weathering $\mathrm{k}_{2}$, leading to the following equation for the acceleration factor $\mathrm{AF}_{\text {temp: }}$ :
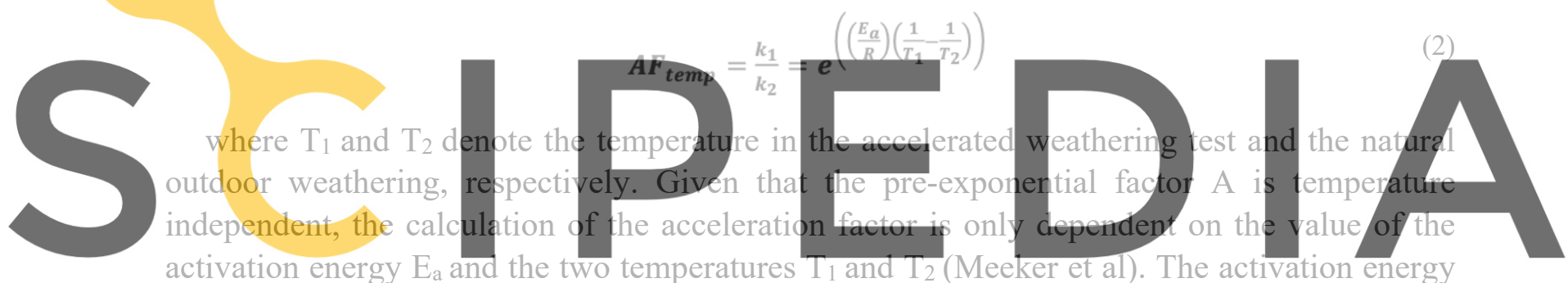

activation energy $\mathrm{E}_{\mathrm{a}}$ and the two temperatures $\mathrm{T}_{1}$ and $\mathrm{T}_{2}$ (Meeker et al). The activation energy Register is strongly dependent on the material composition, the interaction between different, chemical for free at https/ www.scipedia.com to download the version without the watermark agents, the presence of catalysts, and hence very challenging to estimate for a complex material.

However, for the purpose of this study four different activation energies have been used for the calculations: $72 \mathrm{~kJ} /(\mathrm{mol} \mathrm{K}$ ) (as suggested by Riahinezhad et al., 2019), $90 \mathrm{~kJ} /(\mathrm{mol} \mathrm{K}), 60$ $\mathrm{kJ} /(\mathrm{mol} \mathrm{K})$ and $50 \mathrm{~kJ} /(\mathrm{mol} \mathrm{K})$.

The following assumptions and approximations are taken in the investigation of the acceleration factor:

- The pre-exponential factor A in Equation 1 does not vary during the degradation process.

- The calculations are solely based on thermal degradation.

- The reaction mechanism, and hence the activation energy, does not vary during the degradation process.

- The chosen values for $E_{a}$ are either chosen from literature $(72 \mathrm{~kJ} /(\mathrm{mol} \mathrm{K})$ from Riahinezhad et al., 2019) or parametrically assumed in order to explore the influence of the activation energy on the overall result.

- The temperature values for the outdoor exposure is based on average hourly values.

Acceleration factors are calculated based on Equation 2 for four different laboratory test temperatures $\mathrm{T}_{1}=60^{\circ} \mathrm{C}, 70^{\circ} \mathrm{C}$ and $80^{\circ} \mathrm{C}$ and an effective outdoor temperature $\mathrm{T}_{2}$, where the lowest included temperature is $0^{\circ} \mathrm{C}$, assuming that thermal degradation processes below $0^{\circ} \mathrm{C}$ might be neglected for the purpose of this study. 


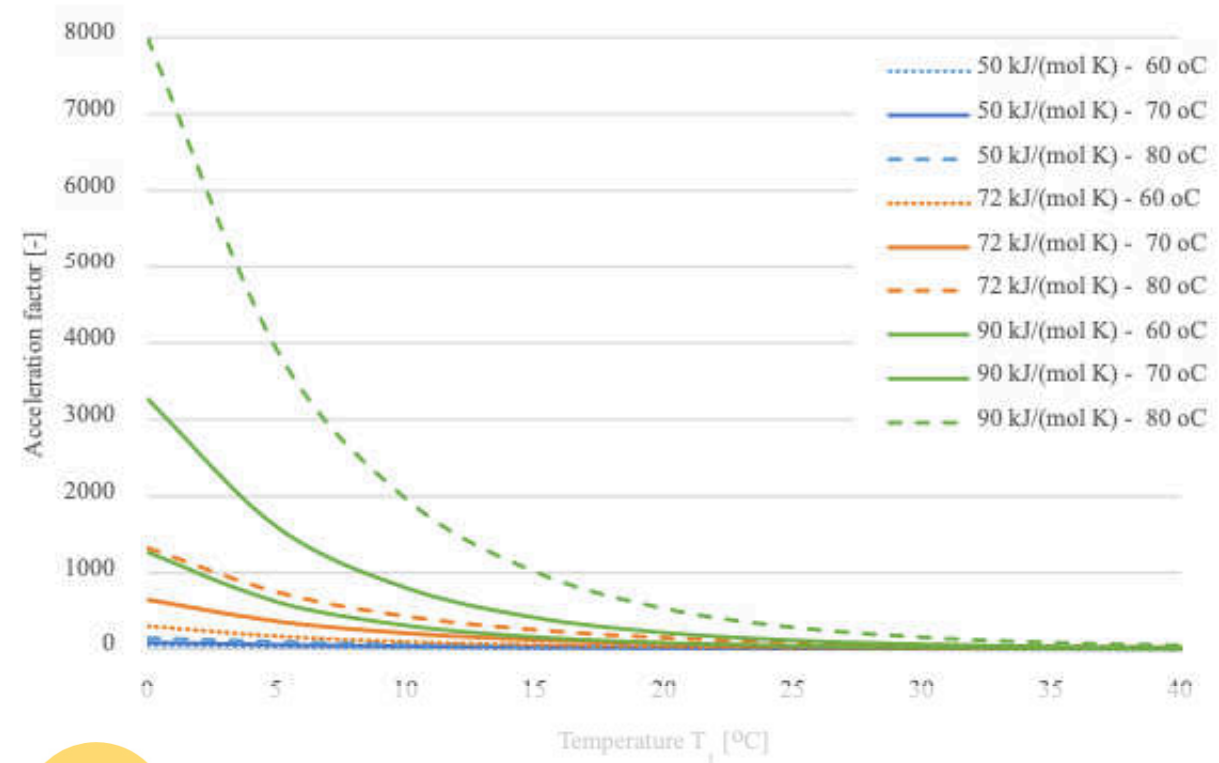

Figure 2. Acceleration factors plotted against average outdoor temperature for $80^{\circ} \mathrm{C}$ (dashed line), $70^{\circ} \mathrm{C}$ ( $\mathrm{solid}$ line) and $60^{\circ} \mathrm{C}$ (dotted line) laboratory test temperature for different activation energies.

The value of the acceleration factor AF depends (given the assumptions and approximations stated in section 4.1) solely on the activation energy $E_{a}$ and the two temperatures $T_{1}$ and $T_{2}$. Table 2 shows the acceleration factors calculated for an activation energy of $72 \mathrm{~J} /(\mathrm{mol} \mathrm{K})$ for different temperatures $\mathrm{T}_{1}$ and $\boldsymbol{T}_{2}$. Figure 2 show $\mathrm{E}_{\mathrm{a}}$.

In the further cours $\mathrm{E}_{\mathrm{a}}=72 \mathrm{~kJ} /(\operatorname{mol} \mathrm{K})$, considered, the acceleration factor varies betv
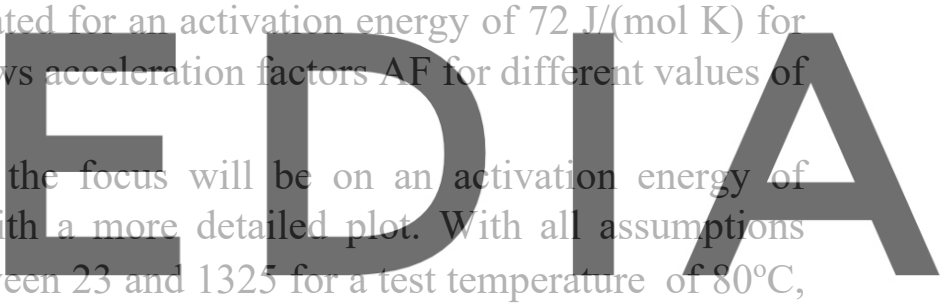
11 and 648 for a test temperature of $70^{\circ} \mathrm{C}$ and between 5 and 304 for a test temperature of $60^{\circ} \mathrm{C}$.

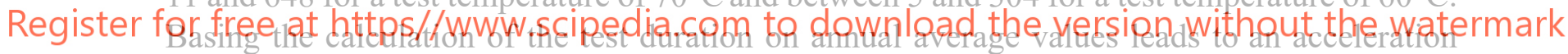
factor of 379 for historic $\left(\mathrm{T}_{2}=4,7^{\circ} \mathrm{C}\right)$ and $225\left(\mathrm{~T}_{2}=9,4^{\circ} \mathrm{C}\right)$ for future climate scenarios (for $\mathrm{E}_{\mathrm{a}}=72 \mathrm{~kJ} /(\mathrm{mol} \mathrm{K})$ and $70^{\circ} \mathrm{C}$ test temperature $)$, leading again to a laboratory test duration of 28 days and 48 days.

Table 2. Acceleration factors $A F$ for $E_{a}=72 \mathrm{~J} /(\mathrm{mol} \mathrm{K})$.

\begin{tabular}{cccc}
\hline $\mathbf{T}_{2}\left[{ }^{\circ} \mathrm{C}\right]$ & & $\mathbf{T}_{\mathbf{1}}\left[{ }^{\circ} \mathrm{C}\right]$ & \\
\hline & $\mathbf{6 0}$ & $\mathbf{7 0}$ & $\mathbf{8 0}$ \\
\hline $\mathbf{0}$ & 304 & 648 & 1325 \\
$\mathbf{5}$ & 172 & 366 & 749 \\
$\mathbf{1 0}$ & 99 & 211 & 432 \\
$\mathbf{1 5}$ & 58 & 124 & 254 \\
$\mathbf{2 0}$ & 35 & 74 & 152 \\
$\mathbf{2 5}$ & 21 & 45 & 93 \\
$\mathbf{3 0}$ & 13 & 28 & 57 \\
$\mathbf{3 5}$ & 8 & 18 & 36 \\
$\mathbf{4 0}$ & 5 & 11 & 23 \\
\hline
\end{tabular}




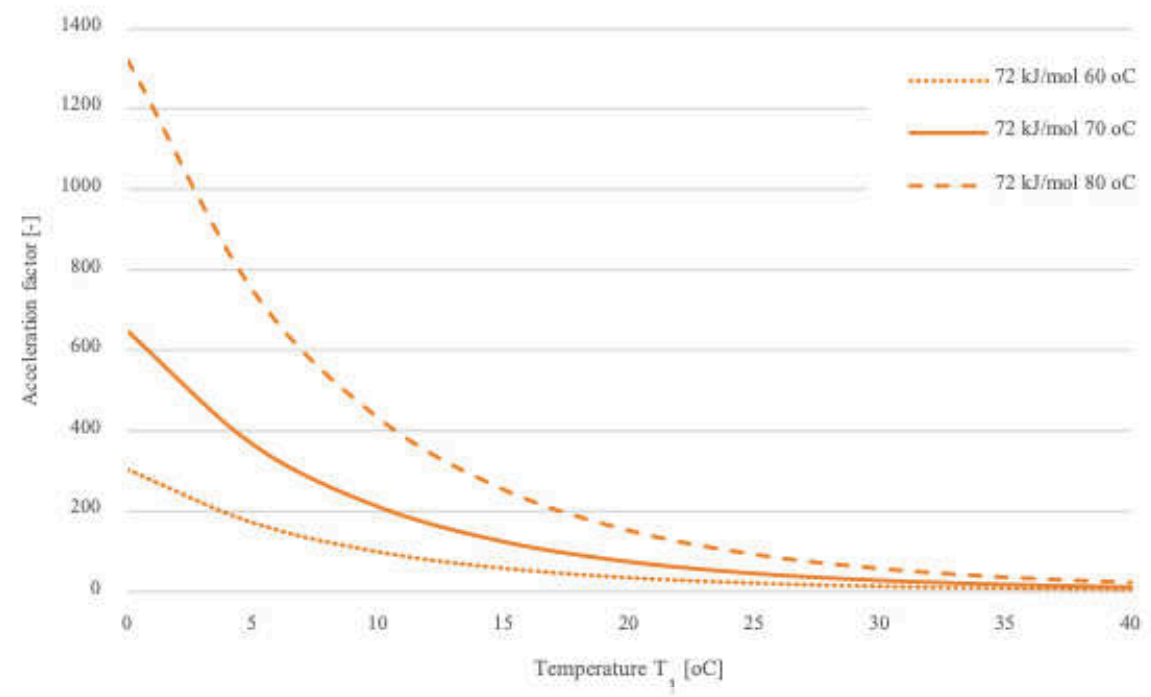

Figure 3. Acceleration factor plotted for $\mathrm{E}_{\mathrm{a}}=72 \mathrm{~kJ} /(\mathrm{mol} \mathrm{K})$ for three different laboratory test temperatures for average outdoor temperatures between $0^{\circ} \mathrm{C}$ and $40^{\circ} \mathrm{C}$.

\section{Laboratory Test Duration}

In order to estimate a laboratory test duration, an average temperature representing the outdoor temperature during the test period is to be calculated. The temperature data is divided into temperature ranges of $5^{\circ} \mathrm{C}$ between $0^{\circ} \mathrm{C}$ and $40^{\circ} \mathrm{C}$ (assuming that the thermal degradation processes below $0^{\circ} \mathrm{C}$ might be neglected). Further, the average temperature for ench interval and the according duration is derived from the climate data. For the calculation of the acceleration factor for the respective temperature range, $\mathrm{T}_{2}$ is set to the average temperature of
the respective interval.

The results of the calculation are shown in Figure 5 for three different laboratory test

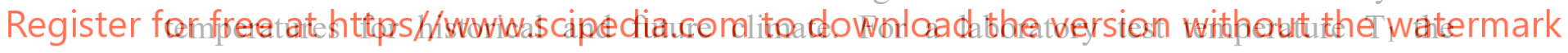
laboratory test duration (for a simulation of a 30-year outdoor test period) is 49 days based in historical climate scenarios and increased to 94 days based on future climate scenarios. 


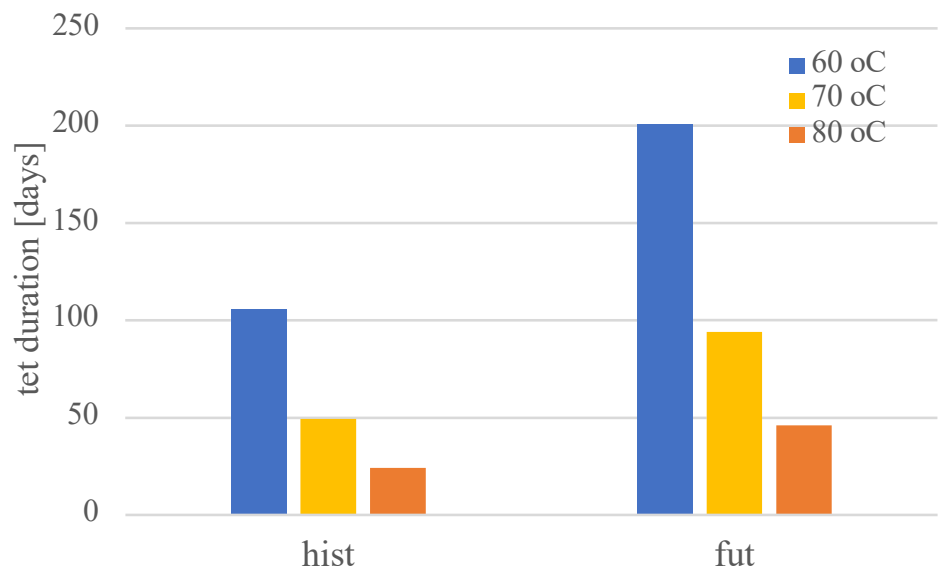

Figure 4. Laboratory test duration [days] for three different laboratory test temperatures $\mathrm{T}_{1}$ based on historic and future climate scenarios.

With a calculation of the outdoor temperature $T_{2}$ in the above described way, the duration of the accelerated test is based on shorter time intervals with their respective duration based on hourly mean values. This contributes to a more accurate calculation, compared to e.g. using and average monthly or annual values, where the calculated test duration is considerably shorter (see section 4.1).

Due to the uncertainty in estimations of acceleration factors, test procedures for durability evaluation in product standards or for certification purposes normally specify longer test periods

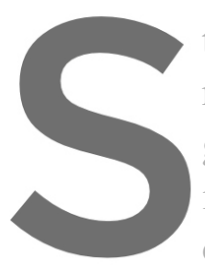
than those calculated fir margin to be on the safe goal of the test is to ass in the end use environment rather than specify durability testing may becomesmaller in the
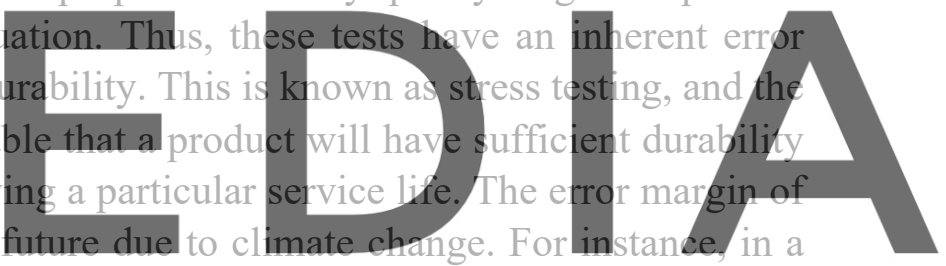
common test method for roofing membranes (EN 1296, 2000), the temperature during the

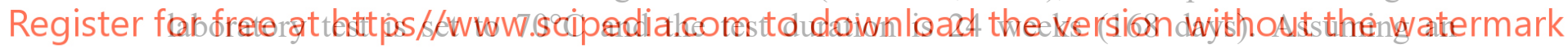
activation energy of $72 \mathrm{~kJ} /(\mathrm{mol} \mathrm{K})$ this test roughly corresponds to an outdoor exposure period of 102 years based on historical climate data. Based on the future climate scenario, however, the laboratory testing would only correspond to 53 years of outdoor exposure.

\section{Conclusions}

The results show a significant influence of the increasing temperature on the accumulated amount of time where certain temperature threshold values are exceeded. For the Calgary data, where the historic average temperature is $4.7^{\circ} \mathrm{C}$ and the future average temperature over a 30 year time period is $9.4^{\circ} \mathrm{C}$, the increase in amount of days where the threshold value exceeds $30^{\circ} \mathrm{C}$ is from 30 to 352 .

In a durability test, based on the calculated acceleration factors, given a number of assumptions, based on thermal degradation and on historic climate data for Calgary, 49 days account for an outdoor test period of 30 years. Based on future climate data, the test duration must be increased to 94 days.

Compared to a commonly used laboratory durability test for roofing membranes (EN 1296, 2000), the test duration of 24 weeks (168 days) accounts for an outdoor test period of 102 years for historical climate and 53 years for future climate.

This calculation shows that future climate scenarios should be considered when designing laboratory experiments. 


\section{Future Work}

This work is based on temperature data measured at a meteorological station. In order to account for microclimate at the exact location where the material in question is applied, it would be interesting to study the differences for temperature values. Also, different geographical locations and their future climate scenarios need to be explored to take into account different climate zones. The further exploration of degradation processes in order to deepen the understanding of thermal degradation and possible interactions between thermal degradation and other climatic strains needs to be further explored.

\section{Ackowledgements}

This study was funded by the project 'TightEN - Durable adhesive airtight solutions for energyefficient building envelopes' (www.tighten.no), the aim of developing robust test, evaluation and prediction methodologies for to ensuring durable adhesive airtight solutions for energy efficient building envelopes. Research Council of Norway; Country: Norway; Grant number: 294894.

\section{ORCID \\ Petra Rüther: https://orcid.org/0000-0003-0245-6813 \\ Klodian Gradeci: https://orcid.org/0000-0002-9837-3512 \\ Malin Sletnes: https://orcid.org/0000-0001-8458-4653 \\ References}
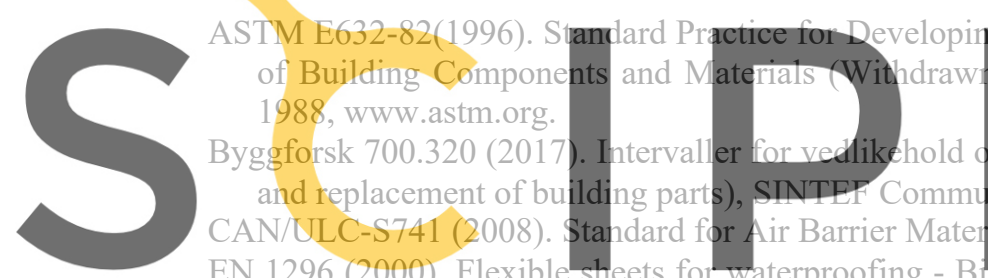

CAN $1296(2000)$ Flexible 1296 (2000). Flexible-sheets for waterproofing - B
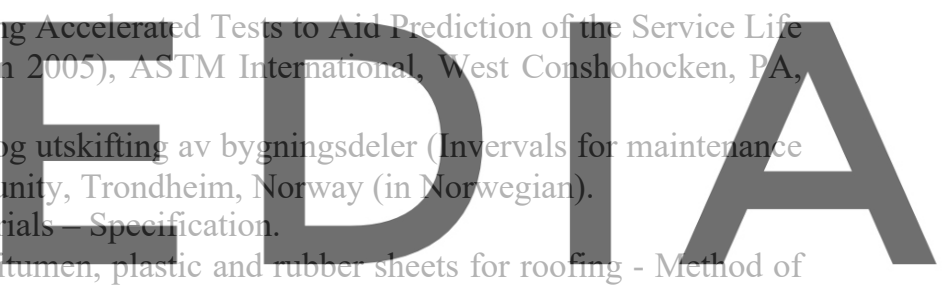
artificial ageing by long term exposure to elevated temperature. The European Standardization Organization.

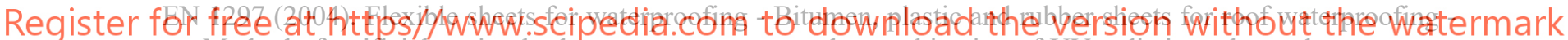
Method of artificial ageing by long term exposure to the combination of UV radiation, elevated temperature and water. The European Standardization Organization.

EOTA TR 010 (2004). Exposure procedure for artificial weathering. EOTA European Organisation for Technicai Approvals.

ETAG 004 (2013). External Thermal Insulation Composite Systems (Etics) with Rendering, EOTA. European Organisation for Technical Approvals.

Gaur, A., Lacasse, M. and Armstrong, M. (2019). Climate Data to Undertake Hygrothermal and Whole Building Simulations Under Projected Climate Change Influences for 11 Canadian Cities. Data, 4(2), 72.

Meeker, W.Q., Escobar, L.A. and Chan, V. (2002). Using accelerated tests to predict service life in highly variable environments. In Jonathan W. Martin and David R. Bauer, Editors, Service life Prediction. Methodology and Metrologies, 805 of ACS Symposium Series, 396-412. American Chemical Society, Oxford University Press.

NS 8140:1985 (1985). Method of exposure of building components and building materials to accelerated climatic strains in a vertical position. The Norwegian Standardization Organization.

NT BUILD 495 (2000). Building materials and components in the vertical position: Exposure to accelerated climatic strains, Nordtest.

Riahinezhad, M., Eve, A., Armstrong, M., Collins, P. and Masson, J.F. (2019). Field temperature and moisture loads from a building envelope as the basis for accelerated aging of barrier membranes. Canadian Journal of Civil Engineering, 46, 969-978. https://doi.org/10.1139/cjce-2018-0757. 